\title{
Application of Smart Technologies in Croatian Marinas
}

\section{Livia Maglića, Ana Grbčića, Lovro Maglića, Ana Gundićb}

The objective of this research is to analyse smart technologies implemented in Croatian marinas and their impact upon the safety and service quality improvement, sustainability, and environmental protection, as well as energy consumption and operations optimisation. Key performance indicators and a definition of smart marina concept have been derived based on the smart port concept. The analysis has been conducted on a sample of 78 marinas in six different counties along the Croatian coast. Ultimately, the SWOT analysis has been performed in order to determine the advantages and disadvantages of introducing smart technologies in marina management. The results indicate that the Croatian marinas are undergoing a revolution in terms of facilitating booking management process and achieving greater safety and service quality, but still need to improve in the field of monitoring and controlling nautical tourism impact upon the environment.

\section{KEY WORDS}

$\sim$ Croatian marinas

$\sim$ Digitalization

$\sim$ Smart technology

$\sim$ Service quality a. University of Rijeka, Faculty of Maritime Studies, Rijeka, Croatia

e-mail: livia@pfri.hr

b. University of Zadar, Maritime Department, Zadar, Croatia

e-mail: agundic@unizd.hr

doi: 10.7225/toms.v10.n01.014

This work is licensed under (cc) BY

Received on: Jul 13, 2020 / Revised on: Dec 26, 2021 / Accepted on: Feb 1, 2021 / Published: Apr 20, 2021

\section{INTRODUCTION}

Marinas are the most valuable part and starting points of nautical tourism development. Emerging trends in terms of new technologies, systems, and solutions have induced a need for making them smarter. Facing increasing pressure to optimise their performance, they strive to deal with economic and functional challenges that impact their sustainability (Molavi et al., 2019). Consequently, associated issues arise, regarding operations, environment, energy, safety, and security (Bucak and Kuleyin, 2016). With an increase in nautical tourism demand, congestion occurs due to a greater number of vessels (especially in high season), causing delays in the arrival/departure of vessels at/from berths. If there is a lack of information sharing in the system, the marina management has to deal with operating errors. Furthermore, a larger number of vessels in the marina leads to higher environmental pollution (air, noise, waste, water) and an increase in energy consumption (electricity and water), resulting in higher costs for both the marina management and the vessel owner (Dragovic et al., 2016). Therefore, there is a need for a comprehensive overview of activities in the marina which will enable a more efficient work organization, with an emphasis on the safety of vessels and marina users. In terms of security, control, and supervision the activities in the marina are the key elements (Shin and Kim, 2014).

As the number of moorings exponentially grows, marinas must be able to cope with dynamic changes. By finding an appropriate way of managing it is possible to find the opportunity for higher profit, which simultaneously means lower costs. This directly brings to the factor that encourages the implementation of smart technology in marinas - the demand for a better service. The satisfaction of the boaters is a key indicator of service quality in the marina. Since the boaters choose the destinations on their own, marinas must assure and constantly provide a high level of service. For a very long time, it was thought that building a 
marina was enough to attract boaters. Today, a marina without a defined and anticipated strategy cannot survive the intensity of international competition. Therefore, a need for making a marina "smart" is recognized to simplify and speed up numerous operations that have been performed physically so far, thus losing precious time that could be spent more productively. This can be successfully done by complementing physical operations with smart digital processes to produce better results. Adopting such a dual approach provides substantial benefits both for the optimisation of physical infrastructure, as well as managing processes. For instance, expanding capacity by increasing the number of berths and facilities in the marina could be very costly without the support of digital technology and predictive analysis. Intelligent technologies offer a clear insight into the impacts those investments could have in reality. As a result, a considerable amount of money and time saved through digitalisation could be invested in maintenance and infrastructure projects, focusing on improving service efficiency.

In terms of managing the marina, "smart" means are becoming more attractive and competitive, which includes minimising the waste of time, money, space, and resources, i.e. optimising the processes, therby making the most of available resources with minimal efforts (PortTechnology, 2016). These factors correspond to the current challenges on the nautical market such as spatial limitations, financial constraints, impact on productivity, eco-awareness, and sustainability (Acciaro et al., 2014). The development of smart marinas requires the integration of infrastructure, working processes, and employees into a unique complex system, to capture information from all resources (Roh et al., 2016). To optimise marina management, introducing a cloud-based information and communications platforms is a must (Lam and Notteboom, 2014). Hence, an internal cloud is a platform that gathers all the data concerning the activities related to the marina. For that purpose, the key innovative technologies such as the Internet of Things (loT), Big Data, Artificial Intelligence (Al), and similar havea been used. Monitoring, data capture, and anticipation are used to make better decisions and improve processes (Fantana et al., 2013). Embracing new technologies, marinas achieve a higher level of process automation, which enables a better capacity utilization and directly impacts business efficiency and improves the overall performance (Chiu et al., 2014). What exactly the loT provides to marinas is a clear return on investment and taking the user experience to a new level. The loT technology in a marina can affect reducing emissions, noise, and waste, optimise resources management, maintenance, and a plan of infrastructure and superstructure. Using Artificial Intelligence, the operations in the marina become safer, more reliable, and less dependent on human failure. The ability to effectively share data results in a greater benefit both for the marinas and its users. The aplication of intelligent solutions optimises the information flow in the marina, directly affecting effectiveness gains. In other words, this will encourage the increase in revenues and the number of vessels on a permanent berth or in transit (Yau et al., 2020). Planning the operations proactively and keeping the entire marina area under control is possible only by interlinking the information and communication systems. It is up to each marina to decide whether to use methods of smarter practices or to implement smart technologies together with physical infrastructure, and to what extent - the goal always being the same - to achieve greater efficiency, productivity, and safety, as well as to improve performance, economic competitiveness, and environmental sustainability.

\section{METHODOLOGY}

In this paper, we have examined and analysed the smart technologies implemented in Croatian marinas across the Adriatic coast. To conduct the analysis, a smart marina concept has been defined based on Smart City and Smart Port concepts, which have already been developed and applied in practice. In order to measure the efficiency in marinas, key performance indicators (KPIs) have been derived from Smart City and Smart Port concepts and presented in table 1, focusing upon the operations energy consumption and the environment. Afterward, an overview of smart technologies used in marina management has been given with emphasis on process automation and safety.

The analysis of smart technologies in Croatian marinas has been performed on a sample of 78 marinas. However, in table 2, only the most significant Croatian marinas have been analysed in more detail, among which 22 marinas are operating the in the Adriatic Croatia International Club $(\mathrm{ACl})$, the largest marina system in the Mediterranean and the leading Croatian nautical company, while remaining nine represent the most innovative Croatian marinas outside the $\mathrm{ACl}$. All relevant data regarding Croatian marinas have been collected from official marina websites and the Croatian Bureau of Statistics. Once we analysed smart technologies already implemented in Croatian marinas, we have proceeded with SWOT analysis pointing out strengths, weaknesses, opportunities, and threats of implementating the smart technologies in Croatian marinas.

\section{SMART MARINA CONCEPT: DEFINITION AND KEY PERFORMANCE INDICATORS}

The emergence of smart technologies in ports imposed an increasing need for adopting smart solutions in marinas as well. To adequately handle the existing problems, marinas are starting to implement new approaches and technology-based solutions for planning and managing operations, known as smart marina concept. The concept of the smart marina has evolved from the smart port concept, which can apply to marinas to some extent 
but have to be adapted to the needs of the nautical tourism market. On the other hand, the Smart Port concept is based on the Smart City concept, containing three main areas with easily measurable key performance indicators (KPIs) as follows: Operations, Energy Consumption, and Environment (Pavlic et al., 2014). According to that, European Sea Ports Organisation
(ESPO) and the ports participating to the EcoPorts network regularly monitor the environmental priorities of European port authorities (Figure 1) to identify the high priority environmental issues and set the framework for guidance and initiatives to be taken by ESPO (Scientific Enterprises Ltd, 2015).

Figure 1.

Environmental priorities of European ports, Source: ESPO Environmental Report (2019).

Environmental priorities of European ports have been the same over the last three years, but some of their relative positions have varied. For instance, climate change has risen from position ten (2017) to the third position in 2019, while air quality and energy consumption has occupied the first and second positions since 2013 and 2016 respectively (ESPO Environmental Report, 2019). The climate change increasing trend shows that complying with climate regulations, reducing carbon emissions, and making infrastructure climate-proof are high priorities for European ports. Although noise has dropped down one position compared to the three previous years, it remains an important issue, especially for citizens living very close to port areas. Furthermore, the relationship with the local community is becoming increasingly significant to ports in terms of environmental quality, living standards, and port development. Ship waste and garbage/port waste have been the most monitored indicators for more than five years, giving clear evidence of ports' readiness to contribute to addressing marine litter which is becoming a great concern for local communities and civil society (Tzay-An Shiau and Chia-
Chin Chuang 2015). In comparison with previous years, port development (land-related) and water quality have decreased in priority, whilst dredging operations have remained in the same position (ESPO Environmental Report, 2019).

The Smart Port concept can be transformed into the Smart Marina concept by retaining the aforementioned main areas of Smart City concept and by altering KPIs on the Operations and Energy consumption areas (Table 1). Since marinas can receive various types of vessels, the main problem is to adequately handle and organise the process of vessels' arrival and departure, as well as their maintenance. Using smart technologies and adopting innovative management strategies, smart marina is increasing in productivity. As the number of vessels in the marina increases year after year, marina management has to optimise capacity utilisation to increase effectiveness and minimise the associated costs. By replacing human workers with automated machinery, human errors, safety issues, and congestions are reduced, thus increasing the service quality, safety, and security in the marina. 
Table 1.

The KPIs by area.

Source: Adapted by authors according to Scientific Enterprises Ltd (2015).

\begin{tabular}{|c|c|c|c|}
\hline Main area & KPI & Smart Port & Smart Marina \\
\hline \multirow[t]{8}{*}{ Operations } & Berth productivity & $\checkmark$ & \\
\hline & Infrastructure productivity & $\checkmark$ & $\checkmark$ \\
\hline & Capacity for receiving large vessels & $\checkmark$ & $\checkmark$ \\
\hline & Size and use of maximum capacity & $\checkmark$ & $\checkmark$ \\
\hline & Technologic level & $\checkmark$ & $\checkmark$ \\
\hline & Level of automation & $\checkmark$ & $\checkmark$ \\
\hline & Level of intermodality Lines calling at the port & $\checkmark$ & \\
\hline & Quality, safety and security & $\checkmark$ & $\checkmark$ \\
\hline \multirow[t]{8}{*}{ Energy Consumption } & Total consumptions of energy & $\checkmark$ & $\checkmark$ \\
\hline & Energy consumption by containers & $\checkmark$ & \\
\hline & Energy consumption by vessels & & $\checkmark$ \\
\hline & Energy consumption by offices & $\checkmark$ & $\checkmark$ \\
\hline & Energy consumption by lighting & $\sqrt{ }^{*}$ & $\sqrt{ }^{* *}$ \\
\hline & $\begin{array}{l}\text { Energy consumption by the terminals equipment for } \\
\text { movement of containers }\end{array}$ & $\checkmark$ & \\
\hline & Use of renewable & $\checkmark$ & $\checkmark$ \\
\hline & Energy management & $\checkmark$ & $\checkmark$ \\
\hline \multirow[t]{6}{*}{ Environment } & Environmental management systems & $\checkmark$ & $\checkmark$ \\
\hline & Wastes management & $\checkmark$ & $\checkmark$ \\
\hline & Water management & $\checkmark$ & $\checkmark$ \\
\hline & Emissions to air & $\checkmark$ & $\checkmark$ \\
\hline & Noise pollution & $\checkmark$ & $\checkmark$ \\
\hline & Leaks and spills of polluting substances at sea & $\checkmark$ & $\checkmark$ \\
\hline${ }^{*}$ port terminal area; ${ }^{* *}$ & harea & & \\
\hline
\end{tabular}

Marinas are large consumers of energy. Taking into consideration the limitation of energy resources, the smart marina concept endeavours to decrease energy consumption by suggesting the use of renewables. Improving the processes and equipment to require less energy and avoid energy loss leads to a $s$ themore efficient energy consumption and lowers the costs (Molavi et al., 2019). Energy management in a marina achieves continuous improvement in energy performance by continuously monitoring and controlling energy consumption. Environmental management systems (EMS) offer a framework for evaluating, monitoring, and reducing port environmental impact. By implementing alternative fuels and zero-emission technologies for vessels and land transportation means in marinas, harmful air emissions are significantly decreased. Likewise, the noise pollution can negatively impact the natural eco-system if effective actions are not designed and performed in a marina. Since marinas are mainly located in the vicinity of residential areas, one of the major environmental concerns is wastewater. Therefore, effective waste and water management are needed to reduce the number of pollutants in marinas. Fast information flow about vessels' traffic flow facilitates decision making for marina managers and users. For a successful implementation of the smart marina concept in practice, it is necessary to use innovative technologies that provide greater efficiency and sustainability by real-time data collection, processing, and sharing (Hiranandani, 2014). 


\section{APPLICATION OF SMART TECHNOLOGIES IN MARINA MANAGEMENT}

In recent years, the state-of-the-art cloud technology is used to provide reliable business models for efficient marina management. Innovative technology helps the marina to be more productive and optimises its operational processes. Managing a greater number of vessels and berths is very challenging and sometimes causes operational problems, aggravating the managers to keep the system stable. Many formal activities have to be coordinated and performed in a short time, such as making contracts, billing, accounting, reporting, and maintenance, while simultaneously fulfilling different clients' requirements. Therefore, the application of smart technologies in marina management is needed to connect all departments into one functional platform unit, thus improving communication by speeding up the information flow, giving a clearer overview of processes in the marina.

Process automation enables the marina to optimise its operations by making better use of time and capacity. By examining the database, relevant statistics can be extracted and detailed data analysis made for a specific period. In that case, business decisions are made faster with much greater certainty since they are based on verified facts and conclusions. Better business decisions mean better service and consequently higher profit, which directly impacts marina competitiveness and its overall effectiveness. Also, the great advantages of smart systems in marina management are flexibility and mobility, since they can be installed on various interfaces and devices. Such systems are easily adaptable to the dynamic changes that are daily present in the marina environment. In such a way, managers have an insight into the business 24 hours a day, meaning that they can promptly react in emergencies, even when they are not physically in the marina area. Using intelligent technologies, less effort and time is needed to perform formal tasks, such as written communication with customers. This whole process is automated since the system uses various professional templates and easily monitor all correspondence.

One of the most important criteria both for customers and managers is safety, in terms of safety at sea, the safety of the vessel, and environmental safety. To ensure maximum safety, prevent environmental pollution, and achieve sustainable development, the following smart sensors are more often applied in marinas:

- Smart battery sensor

- Smart bilge sensor

- Smart smoke sensor

- Smart heat sensor

- Smart water sensor

- Berth occupancy sensor

- Weather conditions sensor.

Smart sensors enable monitoring and controlling of vessels' condition 24/7 (Krpetic et al., 2012). Whenever there is a safety issue detected, the staff is immediately informed via e-mail, voice call, and notification. Generating alerts allows quick reaction of marina staff to prevent accidents that can endanger the safety of customers, the environment, and the infrastructure in the marina. Marina staff regularly performs the so-called dock walks to check the status of vessels and berths in the marina. It takes quite a time to put the information about each vessel and berth together without using smart systems. With Dock Walk feature, every activity performed on the vessel is automatically logged straight into the system with a description and a photo of the vessel. This gives a simple and transparent overview of operations done, such as repairs and maintenance on a particular vessel and berth, both for marina staff and customers, making it a lot easier for managers to plan and organise the execution of individual operations in the marina, as well as tracking the performance. The system also records the list of employees who have checked a particular vessel and carried out the required operations on it, thus providing managers with an insight into the performance of each employee, which may affect their future progress and career development.

Additionally, some marina management software offers docking assistance, automation of the check-in and check-out procedure, as well as the connection with power pedestals for controlling water and electricity consumption. These possibilities make it easier for boaters to access the marina and to plan their activities in the marina. Time saved can rather be spent using the facilities in the marina, which will increase both the customers' satisfaction, as well as the service quality and the marina's incomes. Monitoring of the available and occupied berths is still being done manually in most marinas. Using berth occupancy sensors, the marina staff can easily operate the marina via an onscreen map displaying the status of each berth, thus optimising the process of finding the available berths for a particular vessel (Figure 2). Booking platforms simplify the entire process of finding appropriate berths for different types of vessels and allow clients to manage their reservations and guide them to the booked berth. Various sensors with an emphasis on environmental sustainability have been developed so far. Seawater level and seawater quality sensors help with detecting illegal waste, fuel leaks, and other pollution factors in the marina environment, while some of them also monitor energy consumption. Usually, the boaters struggle with finding an available berth in high season due to congestions and changeable weather conditions. Consequently, fluctuations in demand occur, since boaters sometimes have to change the route due to bad weather. Based on the location and characteristics of the boat, the software shows a real-time map of available berths in nearby marinas. Sensors for observing weather conditions can help boaters to plan their sail and managers to adopt in such situations in terms of organisation and optimal capacity utilisation. 


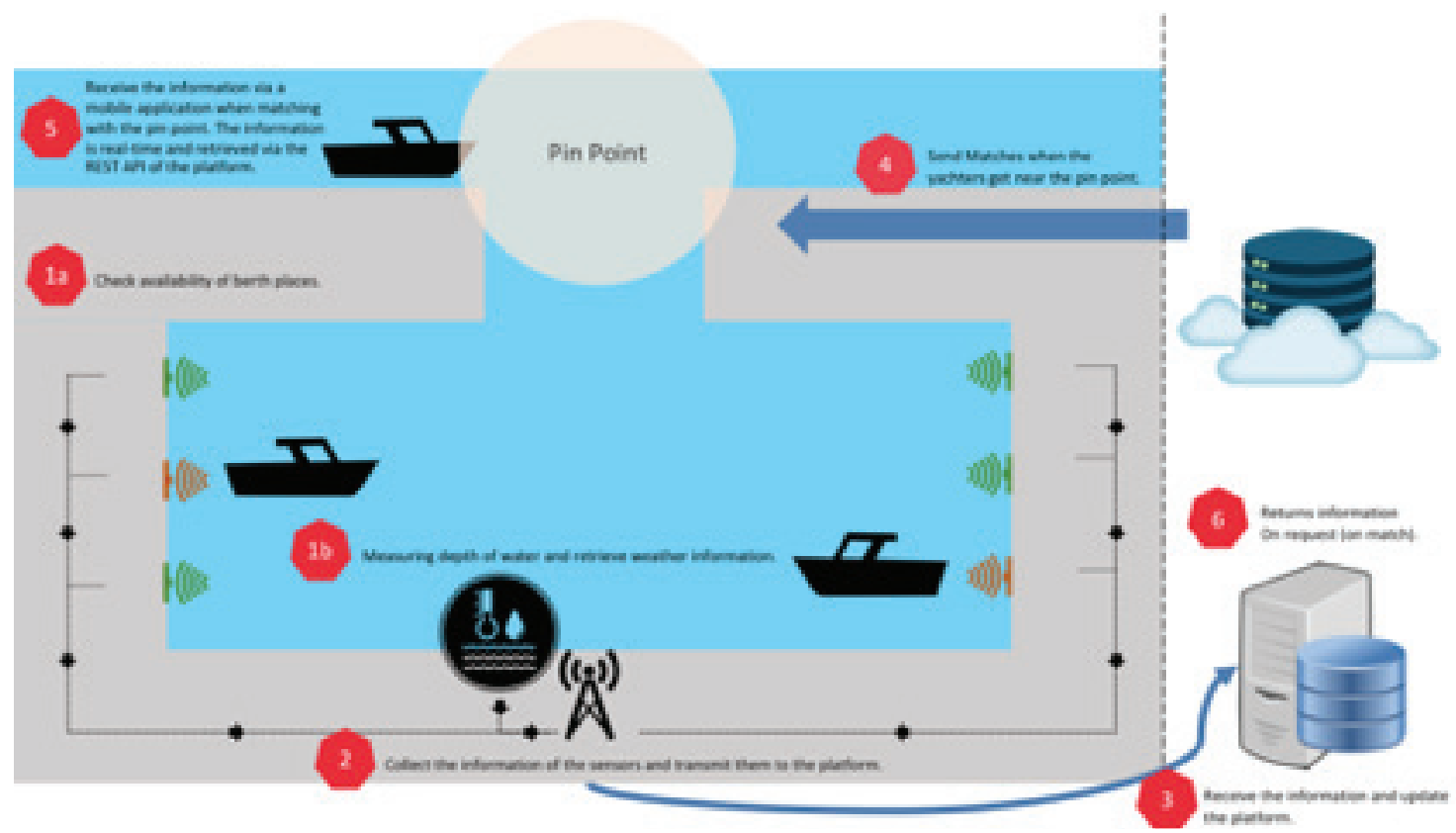

Figure 2.

Interaction of online booking and smart sensors, Source: MatchMore (2018).

Some smart solutions offer simple and comprehensive marina management through different modules, covering various departments such as reception, movement control, booking, Customer Relationship Management (CRM), repair and maintenance, accounting, retail, charter, accommodation, etc. Smart technology enables marina managers to control the vessels' movements and berths' condition, to monitor arrivals and departures of vessels, graphically displaying the vessels' movement history. It also provides data about concluded contracts, berth location, sailing permit, open payments, with the ability to create reports and extract relevant statistics to follow and evaluate business performance. Using Radiofrequency Identification (RFID) technology (berth occupancy sensors) it is easier for managers to monitor berth occupancy status and organise vessel arrivals and departures in the marina. This solution is to be upgraded with additional sensors, such as engine sensors to increase the level of vessels' safety. Selecting a particular vessel, a marina staff can easily get the data needed for serving the customer quickly and efficiently. The system shows a preview of all the activities a customer has made regarding his vessel in the marina, such as recent bookings, contact details, invoices, payments, debts, due dates, and similar. Managers also have access to work orders, planned and done operations, stock status, from which statistical analysis can be derived to improve working processes. Apart from the managers' perspective, these solutions can also be used by marina customers, enabling managing bookings, contracts, payments, online check-in/ check-out, as well as providing data concerning the maintenance and repairs. A great advantage is that the system provides the calculation of total costs, which gives a customer insight into the transparent business. All financial transactions are automatically recorded as soon as created. In such a way the system keeps track of both customers' and suppliers' account balances, making it easier for managers to create financial reports. The software collects all data about the vessel and its owner, thus facilitating searching of database and enabling marina staff to provide fast and efficient service. Smart software can be simply used by all management levels, offering complete monitoring of activities related to a marina. All data can be filtered by various criteria (vessel flag, length, etc.), compared for different periods, and then exported to external systems if necessary. In terms of sustainability, smart software automatically collects data about water and electricity consumption at each berth. Such systems, which are constantly updating to provide up-to-date features for successful optimisation of business processes, have already been implemented in nine Croatian marinas.

\section{ANALYSIS OF SMART TECHNOLOGIES IN CROATIAN MARINAS}

Croatian marinas have been outspread all along the coast through six counties as follows: Istria, Primorje-Gorski Kotar, 
Zadar, Šibenik-Knin, Split-Dalmatia, and Dubrovnik-Neretva. In 2019, there are 167 nautical ports on the Croatian coast, including 78 marinas, 75 anchorages, 9 moorings, and 5 boat storages, covering a total water surface area of $4349270 \mathrm{~m} 2$, containing 18179 berths (Croatian Bureau of Statistics, 2019). Compared to 2018 , the total income has increased by $7.2 \%$, and the largest share of $25.4 \mathrm{v}$ in total revenue is recorded in Šibenik-Knin County. Likewise, Šibenik-Knin County is the leading one in the number of vessels on permanent moorings, while Split-Dalmatia County leads in the number of vessels in transit. Furthermore, an increase in the number of vessels on permanent berth by $4.6 \%$, and the number of vessels in transit by $5.5 \%$ has been recorded (Croatian Bureau of Statistics, 2019). Most marinas are open year-round, while only a few of them provide their services exclusively during the tourist season, from mid-March to the end of October. Some of them are built within city seaports or near shipyards, while a couple of new marinas are currently under construction. Due to its convenient geographic location and surroundings such as capes, hills, islands, and peninsulas, many Croatian marinas are naturally sheltered against wind and waves and have a very favorable climate with fairly calm sea currents and tides. However, some marinas require the construction of breakwaters and seawalls due to strong north or south wind blowing occasionally in the Adriatic Sea, potentially causing damage to the vessels and marina infrastructure (Maglic et al., 2019).

In the Adriatic Croatia International Club (ACl), the largest marina system in the Mediterranean and the leading Croatian nautical company, 22 marinas are operating, as shown in Figure 3.

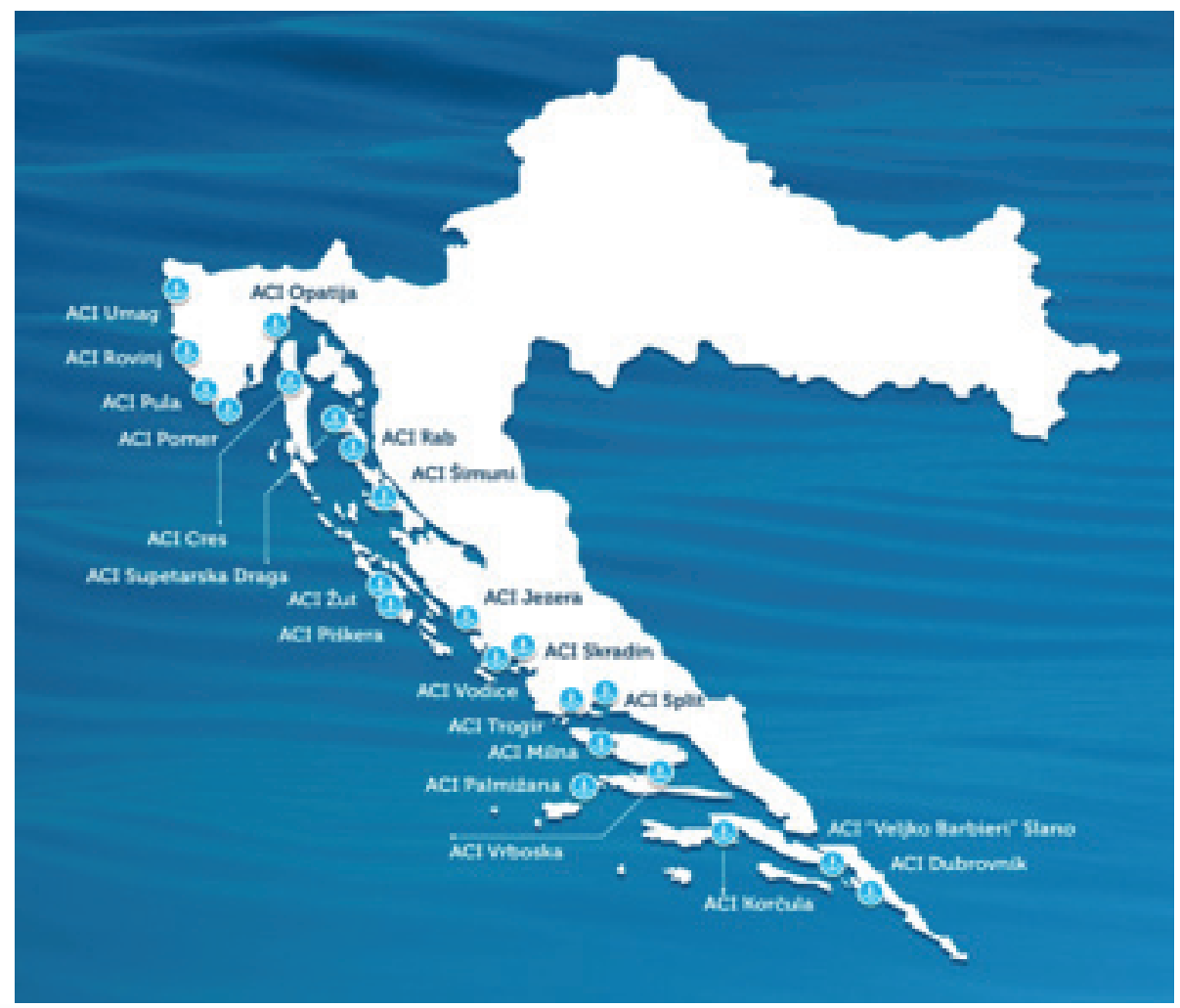

Figure 3.

ACI marinas in Croatia, Source: Adriatic Croatia International Club (2019).

A significant indicator of water purity and environmental awareness in $\mathrm{ACl}$ marinas is the Blue Flag award, owned by ten $\mathrm{ACl}$ marinas. The marinas that stand out, in particular, are Marina Dubrovnik, declared as the marina of the year several times, and Marina Korčula owning the Best Island Marina special recognition. On the other hand, serious attention has been paid to the damaging influence on the marine environment so far. Among 850 samples in 36 marinas, only the following marinas have shown a very good sediment quality: $\mathrm{ACl}$ Marina Korčula, ACI Marina Rab, ACI Marina Rovinj, ACI Marina Vrboska, Marina Borik Zadar, Marina Dalmacija, Marina Poreč, and Marina Šangulin. In all the others, an increased concentrations of one or more elements studied - copper, zinc, arsenic, or lead have been found. The consequences of genotoxic effects have led to an 
increase in the mortality of individuals, reducing population, and genetic variability, thus indicating the problem of environmental pollution. To prevent damages to the marina environment, and improve the managing business, the smart marina concept is being implemented in more and more Croatian marinas. However, smart technologies used in Croatian marinas are mostly aimed at the increasing level of service, safety, and customer satisfaction. Smart solutions applied in marinas across the Croatian coast are shown in Table 2.

Table 2.

Smart solutions in Croatian marinas.

Source: Authors.

Smart technology

Marina

\begin{tabular}{llllllllll}
\hline & Funtana & Nautica & Veruda & Vrsar & Lošinj & Punat & Novi & Pičuljan & Porto Re ACI* \\
\hline e-booking & $\checkmark$ & $\checkmark$ & $\checkmark$ & $\checkmark$ & $\checkmark$ & $\checkmark$ & $\checkmark$ & $\checkmark$ & $\checkmark$ \\
\hline e-payment & $\checkmark$ & $\checkmark$ & $\checkmark$ & $\checkmark$ & $\checkmark$ & $\checkmark$ & $\checkmark$ & $\checkmark$ & $\checkmark$ \\
\hline Smart battery sensor & $\checkmark$ & $\checkmark$ & $\checkmark$ & $\checkmark$ & $\checkmark$ & $\checkmark$ & $\checkmark$ & $\checkmark$ & $\checkmark$ \\
\hline Smart bilge sensor & $\checkmark$ & $\checkmark$ & $\checkmark$ & $\checkmark$ & $\checkmark$ & $\checkmark$ & $\checkmark$ & $\checkmark$ & $\checkmark$ \\
\hline Smart smoke sensor & $\checkmark$ & $\checkmark$ & $\checkmark$ & $\checkmark$ & $\checkmark$ & $\checkmark$ & $\checkmark$ & $\checkmark$ & $\checkmark$ \\
\hline Smart heat sensor & $\checkmark$ & $\checkmark$ & $\checkmark$ & $\checkmark$ & $\checkmark$ & $\checkmark$ & $\checkmark$ & $\checkmark$ & $\checkmark$ \\
\hline $\begin{array}{l}\text { Weather conditions } \\
\text { sensor }\end{array}$ & & & & & & & & $\checkmark$
\end{tabular}

sensor

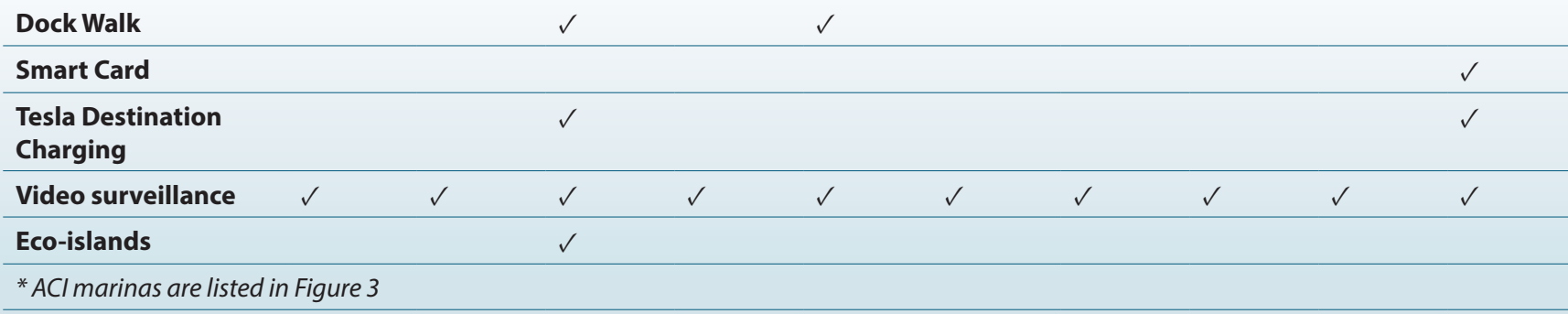

The $\mathrm{ACl}$ system offers an optimisation of nautical route, complete comfort, and a safe berth using up-to-date technology. For that purpose, the $\mathrm{ACl}$ has deployed mobile applications, representing a step forward in terms of functionality for its clients. In addition to the possibility of online booking and payment, this application provides data about facilities, weather forecasts, and free capacities for all $\mathrm{ACl}$ marinas. Furthermore, Smart $\mathrm{ACl}$ Card allows an instant data transfer to the reception, thus shortening waiting times and simplifying the check-in and check-out processes. This technology brings many benefits and discounts, both for permanent berth users and vessels in transit, thereby encouraging an increase in demand. $\mathrm{ACl}$ marinas have also become part of the global network of Tesla Destination Charging - electric chargers for electric cars. Using smart sensors, $\mathrm{ACl}$ marinas offer the service of supervised battery charging, vessel ventilation, and inspection. These actions are followed by sending photographs of the vessel to the owner via e-mail to keep the customer up-to-date with the condition and activities performed on the vessel by the marina staff.
ACIMarina Trogir's business is based on quality management systems that provide a framework for improving service quality to meet the requirements and expectations of customers, as well as other relevant stakeholders in the most efficient way possible. This refers to the performance of repairs, modifications, and maintenance of vessels and providing marina services. Introducing the software in the environmental management system, a marina is enabled to efficiently use available resources and reduce waste, thus gaining customers' trust, but also a better market competitiveness. Furthermore, the software enables rational management, savings, and the introduction of renewable energy resources in the production process. This technology is implemented to reduce and rationalise costs, consequently increasing financial and organizational profits. The software is also used to monitor electricity and water consumption, as well as organizing discharge of tanks and disposal of waste such as fuel, oil, grease, and similar.

With a view to optimising operations, to being more productive and making better decisions, a smart management 
software is applied in the following marinas: Marina Funtana, Marina Veruda, Marina Vrsar, Marina Lošinj, Marina Novi, Marina Porto Re, Marina Punat, Marina Nautica, and Marina Pičuljan, while in Marina Mitan the software is still in the introductory phase. From the aspect of service quality, those marinas offer the installation of smart loT sensors mentioned in the previous chapter (smoke/temperature, bilge, and battery sensors) to detect the state of the vessels' battery. Using this smart technology, the marina staff is allowed to monitor vessels' condition 24/7 and promptly take the actions necessary to make a vessel safe at all times, thereby significantly increasing the level of service.

In Marina Poreč, Tehnomont Marina Veruda, Marina Čikat, Marina Lošinj, Marina Preko, Marina Agana, Marina Frapa, Marina Kaštela, and Marina Lav, management software is implemented to make thhe marina in question more efficient and profitable. This solution enables a complete control of marina management, including berth occupancy sensors. Following the world trends, Marina Frapa has proven that it is environmentally aware and offers high-quality service since it is a multiple winner of several awards for the best Adriatic marina and also a proud partner of the environmental program called the Blue Flag, whose main goal is the preservation and protection of the sea and coast. It ha salso been a partner of the environmental movement called Green Sail since 2018, thereby promoting sustainable tourism development.

In Marina Kaštela, assistance to sailors for easy maneuvre and supervision of vessels is insured 24/7. In addition to video surveillance, Dock Walk feature has been implemented, thus raising the level of control and security in the marina. Environment protection and clear sea are the main goals for the sustainable development of Marina Kaštela, representing the social responsibility of its managers. Therefore, during vessels' handling, wastewater generated by washing and cleaning is treated with a specially designed purifier before discharge. Using innovative technologies, this device treats the wastewater loaded with heavy metals from anti-fouling paints and similar. To increase the safety and security of the vessel, Tehnomont Marina Veruda has introduced a new "smart" vessel tracking system, similar to Dock Walk technology applied in Marina Kaštela, whose functionality is already described in the previous chapter. Likewise, this marina is also environmentally conscious and is implementing smart sensors. It is noticeable that every year the level of waste disposal in the marina decreases. There are charging stations for electric vehicles available in the marina, while marina staff for transporting cargo and customers use means that are not harmful to the environment, such as electric bicycles and mopeds. Marina Veruda collects and recycles municipal waste separately using 6 "eco-islands" for the disposal of hazardous waste, oil, and batteries.

A significant number of accidents occur during the summer tourist season, when domestic and foreign tourists activities at the Croatian coast are most intense, while during the wintertime any misjudgment at sea can often be fatal due to variable weather conditions. The greatest number of distress calls is usually sent by boaters due to the increase in maritime traffic. The three main causes of initiating interventions are strandings, collisions, and inability to navigate (fuel or engine failure, problems with rudders, sails, or rope tangles around the propeller). Further analysis shows that the most common causes of accidents at sea are negligence for weather warnings, sudden storms, insufficient nautical experience, and inadequate boats and yachts equipment.

In order to prevent accidents and achieve a higher level of safety at sea, a multilingual smartphone application is designed for yachtsmen, boat masters, fishermen, divers, swimmers, and other persons spending time at sea. The application enables the user to provide relevant and detailed information to port authorities and other maritime safety and pollution control offices in a simple and fast manner, especially to search and rescue services at sea. On the other hand, users can easily access accurate information on safety at seas, such as the current location, the conditions at sea, the contacts of nearest emergency public services, ports or anchorages, at any time and any place. It also includes contacts, opening hours and geographic location of public services, search and rescue, harbour master's offices, ports, marinas, nautical anchorages, gas stations, border crossings, decompression chambers, embassies and consulates, health care facilities, emergency services, VTS services, coastal radio stations and other essential public and commercial services responsible for safety at sea.

Likewise, the application allows the users to eliminate danger and to obtain urgent help in case of an emergency since it is programmed to operate at all times (24-7) at any position at sea, with the ability to report a maritime offence or other extraordinary events by text message, a photo, short video, and event location. It also works very well even when a user does not have the internet access because the content is loaded on the smartphone while the user is connected to a wireless network. For communicating with the search and rescue service at sea, nIS uses short SMS messages and a telephone call to the toll-free number via available mobile operators, automatically delivering user location via SMS, thus significantly reducing time searching for the injured.

The application provides high-quality weather forecasts for every hour in 72 hours, including air temperature and pressure, wind speed and direction, waves, clouds, etc. Besides, the user has access to various navigational rules, for example, boat equipment, collision avoidance, environmental protection, information for foreign vessels, divers or swimmers, radio service and advertisements, maritime designations. To conclude, using nIS significantly reduces the time required by the navigation services to respond in the event of an accident 
or similar extraordinary events at sea. In this way, it is much easier to identify the perpetrators of a maritime misdemeanor. The application greatly facilitates the availability of public safety services at sea, thereby contributing to the safety of human lives and sea property.

Using innovative technologies, the smart buoy concept aims to enable an effective control of the maritime heritage. Via this concept, the focus is put on controlling the vessels' flow at anchorages in marinas. Furthermore, the plan is to improve the concept to help in increasing safety at sea and protecting the sea against pollution. The main motive for this project is a lack of high-tech solutions on maritime safety, therefore this concept is based on Computer Vision and Artificial Intelligence technology.
This smart buoy will be able to detect illicit behavior at sea, such as speedboating, to assist the injured and to control vessels in national parks. However, it is yet to be implemented in practice.

\section{SWOT ANALYSIS OF SMART TECHNOLOGIES IN CROATIAN MARINAS}

Smart technologies constantly collect, analyse, and use data to provide a higher level of service and to improve marina business performance. SWOT analysis in Croatian marinas has been carried out (Table 3), outlining strengths, weaknesses, opportunities, and threats of the implementation of smart technologies in marina management.

Table 3.

SWOT analysis of Smart technologies in marina management.

Source: Authors.

\begin{tabular}{llll} 
Strengths & Weaknesses & Opportunities & Threats \\
\hline Functionality & Less employment & Increase in demand & Expensive introducing \\
\hline Flexibility & Complexity & Improvement in quality & Expensive maintenance \\
\hline Costs optimization & Data privacy and security & Opening new markets & Hacking vulnerability \\
\hline Sustainability & Heavy data & & \\
\hline Efficiency & & \\
\hline Effectiveness & & \\
\hline Productivity & & \\
\hline Emissions reduction & & \\
\hline Personal safety & & \\
\hline Navigational safety & & \\
\hline Business transparency & & \\
\hline Ease of Use & & \\
\hline
\end{tabular}

Smart technologies are easy to use, transparent, and can be installed on different devices, providing flexibility and functionality for both customers and managers. Since smart solutions save time and offer better capacity utilisation, the workflow is optimised, resulting in higher revenues and lower costs, simultaneously making a marina more competitive and productive. Smart technologies are beneficial to the marina environment since they reduce emissions. For example, e-bicycles and scooters used in Marina Veruda, as well as electric cars charging stations implemented in $\mathrm{ACl}$ marinas, reduce fuel consumption and negative impact on natural resources. For comparison, the world's leading ports use smart lighting connected to motion sensors to reduce electricity consumption. Artificial Intelligence helps in automating and standardising the processes, making them safer and less dependent on human failure, which imposes the problem of less need to employ humans. Since smart marinas have to deal with big data, privacy and security are potential areas of concern. The biggest weakness of any smart technology is the lack of security, threatened by a hacking vulnerability which is impossible to avoid. Since smart technologies rely on the collection of data to improve services, a massive amount of data has to be stored and analysed, causing major data-related issues due to lack of infrastructure. Smart technology brings many advantages, but on the other hand, it is very costly both for introducing and further maintenance. Using smart technologies in marina management will result in service quality improvement which directly impacts customers' satisfaction. Furthermore, greater customer satisfaction induces the increase in demand, making a marina open for new markets. 


\section{CONCLUSION}

In general, Croatian marinas follow the latest modern solutions in the field of marina management, but still on an unsatisfactorily level. The software applications used in Croatia are mainly based on simplifying the entire management process, with emphasis on the safety, maintenance, and meeting the requirements of the vessel and the boater. The existing solutions are mainly focused on facilitating the process of finding and booking a berth, thus saving the marina staff valuable time that can be spent more productively, dedicating more attention to the clients. Based on the analysis of the existing smart technologies mostly mostly applied in Croatian marinas, these consist of e-booking, e-payment, and video surveillance, followed by smart battery, bilge, smoke, and heat sensors. Smart technologies that have so far been rarely implemented are weather conditions sensor, Dock Walk, Smart Card, Tesla Destination Charging, and Eco-islands. However, insufficient attention is still being paid to sensors that should monitor changes and overall state in the marine environment, as well as indicate pollution problems. In other words, the current state in Croatian marinas is as follows: key performance indicators (KPIs) from operations area prevail, followed by energy consumption indicators, while the environmental area indicators are the least present. In conclusion, the main disadvantage of currently implemented systems in Croatian marinas is the insufficient control of the factors affecting pollution, such as emissions, energy consumption, waste, and noise management and that is subject to further analysis.

According to the SWOT analysis, there are several opportunities for improvement in terms of digitalisation in Croatian marinas, such as the increase in demand, improvement in quality, and opening of new markets. With the introduction of smart technologies in Croatian marinas, the service quality is greatly increased, which will attract new customers and retain the existing ones, thereby increasing the competitiveness of the marina and provide opportunities for further sustainable growth and development in line with the new technologies.

\section{REFERENCES}

Acciaro, M. et al., 2014. Environmental sustainability in seaports: a framework for successful innovation. Maritime Policy \& Management, 41(5), pp.480-500. Available at: http://dx.doi.org/10.1080/03088839.2014.932926.

Adriatic Croatia International Club, 2019. ACI marinas, available at: $\underline{\text { https://www.aci- }}$ marinas.com/aci marina/.

Bucak, Umur \& Kuleyin, Barış, 2016. Evaluation of Green Performance Indicators Priority Perception in Terms of Sustainable Port Concept A Comparative Analysis for Turkish Ports.

Chiu, R.-H., Lin, L.-H. \& Ting, S.-C., 2014. Evaluation of Green Port Factors and Performance: A Fuzzy AHP Analysis. Mathematical Problems in Engineering, 2014, pp.1-12. Available at: http://dx.doi.org/10.1155/2014/802976.
Croatian Bureau of Statistics, 2019. Nautical Tourism, Capacity and Turnover of Ports. Available at: https://www.dzs.hr/Hrv Eng/publication/2019/04-03-04 012019.

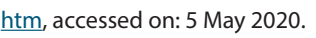

Dragovic, B et al., 2016. Environmental management and monitoring for sustainable development in marinas, 44, pp. 304-312.

ESPO Environmental Report, 2019. EcoPortsinSights 2019. Available at: https:// www.espo.be/media/Environmental \%20Report-2019\%20FINAL.pdf, accessed on: 5 May 2020.

Fantana, N. et al., 2013. Internet of Things - Converging Technologies for Smart Environments and Integrated Ecosystems.

Hiranandani, V., 2014. Sustainable development in seaports: a multi-case study. WMU Journal of Maritime Affairs, 13(1), pp.127-172. Available at: http://dx.doi.org/10.1007/s13437-013-0040-y.

Krpetic, R., Oletic, D. \& Bilas, V., 2012. Wireless sensor network for berth supervision in marinas. 2012 IEEE Sensors Applications Symposium Proceedings. Available at: http://dx.doi.org/10.1109/sas.2012.6166276.

Lam, J.S.L. \& Notteboom, T., 2014. The Greening of Ports: A Comparison of Port Management Tools Used by Leading Ports in Asia and Europe. Transport Reviews, 34(2), pp.169-189. Available at:

http://dx.doi.org/10.1080/01441647.2014.891162.

Maglić, L. et al., 2019. Multi-Criterion Decision Model for Marina Location Selection in the County of Primorje and Gorski Kotar. Naše more, 66(1), pp.28-36. Available at: http://dx.doi.org/10.17818/nm/2019/1.4.

MatchMore, 2018. How to create a smart marina with IoT and proximity-based features. Available at: https://blog.matchmore.io/how-to-create-a-smart-marina/, accessed on: 5 May 2020.

Molavi, A., Lim, G.J. \& Race, B., 2019. A framework for building a smart port and smart port index. International Journal of Sustainable Transportation, 14(9), pp.686-700. Available at:

http://dx.doi.org/10.1080/15568318.2019.1610919.

Pavlic, B. et al., 2014. Sustainable port infrastructure, practical implementation of the green port concept. Thermal Science, 18(3), pp.935-948. Available at: http://dx.doi.org/10.2298/tsci1403935p.

PortTechnology, 2016. What is a Smart Port? Available at: https://www. porttechnology.org/news/what-is-a-smart-port/, accessed on: 5 May 2020.

Roh, S., Thai, V.V. \& Wong, Y.D., 2016. Towards Sustainable ASEAN Port Development: Challenges and Opportunities for Vietnamese Ports. The Asian Journal of Shipping and Logistics, 32(2), pp.107-118. Available at:

http://dx.doi.org/10.1016/j.ajsl.2016.05.004.

Scientific Enterprises Ltd, 2015. Smart Ports \& Smart Marinas solution. Available at: https://www.scienter.gr/web/en/smart ports.php, accessed on: 5 May 2020.

Shiau, T.-A. \& Chuang, C.-C., 2013. Social construction of port sustainability indicators: a case study of Keelung Port. Maritime Policy \& Management, 42(1), pp.26-42. Available at: http://dx.doi.org/10.1080/03088839.2013.863436.

Shin, I., \& Kim, B., 2014. Development Smart Yacht Operational System and Marina Control System for Navigational Safety, International Journal of Information Engineering and Electronic Business, 4(1), pp. 16-21.

Yau, K.-L.A. et al., 2020. Towards Smart Port Infrastructures: Enhancing Port Activities Using Information and Communications Technology. IEEE Access, 8, pp.8338783404. Available at:

http://dx.doi.org/10.1109/access.2020.2990961. 